\title{
Theoretical, Experimental and Numerical Investigations of the Effect of Inlet Blade Angle on the Performance of Regenerative Blowers*
}

\author{
Tarek Abdel-Malak Mekhail1, Omar Mohamed Dahab², Mohamed Fathy Sadik ${ }^{1}$, \\ Mahmoud Mohamed El-Gendi3 ${ }^{3}$, Hesham Sayed Abdel-Mohsen ${ }^{1 \#}$ \\ ${ }^{1}$ Faculty of Energy Engineering, Mechanical Power Department, Aswan University, Aswan, Egypt \\ ${ }^{2}$ Faculty of Engineering, Mechanical Power Department, Aswan University, Aswan, Egypt \\ ${ }^{3}$ Faculty of Engineering, Mechanical Power and Energy Department, Minia University, Minia, Egypt \\ Email: $\underline{\text { h sayed80@aswu.edu.eg }}$
}

Received 10 July 2015; accepted 21 September 2015; published 24 September 2015

Copyright (C) 2015 by authors and Scientific Research Publishing Inc.

This work is licensed under the Creative Commons Attribution International License (CC BY). http://creativecommons.org/licenses/by/4.0/

(c) (i) Open Access

\section{Abstract}

Regenerative machines allow high heads at small flow rates and present performance curves with very stable features. This research includes a study of the effect of four inlet flow angles $\left(90^{\circ}, 115^{\circ}\right.$, $125^{\circ}$ and $135^{\circ}$ ) of the blade at outlet flow angle of $90^{\circ}$ on the performance of regenerative blower at rotation speed of $3000 \mathrm{rpm}$ and at different flow rates. Investigation and comparison of the experimental results with both one-dimensional theoretical model and numerical CFD technique using CFX-ANSYS 16.1 are done. The numerical CFD analysis show that the flow enters the impeller from the blade side (about $65 \%$ of the blade side area) and leaves from the blade tip and blade side (the remaining $35 \%$ from the blade side area). According to this observation, a mathematical model that is based on momentum exchange theory to handle one inlet angle and two exit angles for the regenerative blower impeller blades is proposed. Consequently, the experimental work is carried out by two steps. The first step is done by studying the effect of inlet blade angle of $90^{\circ}$ and analyzing the results by using the CFD analysis. The CFD results show shock losses and vortices behind each blade at the inlet flow regions. To reduce these losses, an increase of the inlet blade angle in a range between $25^{\circ}$ to $45^{\circ}$ is proposed. The second step is the splitting of this angle range to three inlet blade angles of $115^{\circ}, 125^{\circ}$ and $135^{\circ}$ in order to study and analyze the CFD results for these angels. The CFD analysis shows the disappearance of the shock losses and vortices that are formed behind the blade of angle $90^{\circ}$. The experimental results show that the pressure head and the efficiency depend strongly on the blade inlet and outlet flow angles as well as on the blade geometry. The results also show that the best blower performance can be obtained at an inlet flow

${ }^{*}$ This work is carried out at the fluid dynamics laboratory of the Faculty of Energy Engineering, Aswan University, Egypt.

" Corresponding author.

How to cite this paper: Mekhail, T.A.-M., Dahab, O.M., Sadik, M.F., El-Gendi, M.M. and Abdel-Mohsen, H.S. (2015) Theoretical, Experimental and Numerical Investigations of the Effect of Inlet Blade Angle on the Performance of Regenerative Blowers. Open Journal of Fluid Dynamics, 5, 224-237. http://dx.doi.org/10.4236/ojfd.2015.53025 
angle of $125^{\circ}$, and this is confirmed by CFD simulation analysis. Finally, it is shown that the proposed one-dimensional model yield results that are in a good agreement with the experimental results.

Keywords

Regenerative Blower, Circulatory Flow, CFD, Shock Losses, Vortices, Impeller Angles

\section{Introduction}

Regenerative blowers are used widely in many wide ranges of applications. These include: pneumatic conveying, sewage aeration, vacuum lifting, vacuum packaging, packaging equipment, printing presses, aquaculture/pond aeration, spas, dryers, dust/smoke removal, industrial vacuum systems, soil vapor extraction, and chip removal for engraving equipment. Whenever high airflow and low vacuum/pressure are required, regenerative blowers are considered an ideal solution as a properly installed blower that will provide years of service of free operation. Although the efficiency of regenerative blower is not very high, usually less than 50 percent, they are used widely in industry. Some of previous researchers studied theoretically, numerically and experimentally the effects of blade angels on the performance of regenerative blower, but none of them thought about the twisted blades.

Depending on the experimental investigation, Yukio Tomita et al. [1] studied the regenerative pump performance using three vane angles of $60^{\circ}, 90^{\circ}$, and $120^{\circ}$ combining with six impeller diameters from range $94 \mathrm{~mm}$ to $180 \mathrm{~mm}$. They concluded that the influence of impeller diameter on the performance varies with van angle. Hübel et al. [2] conducted a visualization of three-dimensional flow by using the laser light sheet technique in combination with digital image processing. They studied the influence of vane angles of $45^{\circ}, 60^{\circ}$ and $90^{\circ}$ on the performance of regenerative pump. It was also concluded that the vane angle 45 degree has the best efficiency from other studied angles. Badami [3] studied the influence of vane inclination on the performance of regenerative pump, where eleven angels from $45^{\circ}$ up to $135^{\circ}$ were studied theoretically and experimentally. Won Chul Choi et al. [4] studied the effect of inclined blade angles of $0^{\circ}, \pm 15^{\circ}, \pm 30^{\circ}$ and $\pm 45^{\circ}$, and radial chevron impellers with chevron angles of $15^{\circ}, 30^{\circ}$ and $45^{\circ}$ on the optimization of regenerative pump performance. Among all blade configurations tested in their study, the chevron blade angle of around $30^{\circ}$ exhibited the highest head with reasonably good efficiency.

The previous studies did not investigate experimentally the effect of inlet blades angle on the performance of regenerative blower. This research depends on studying experimentally the effect of changing the inlet flow angle for the blade profile that differs from the hub to the tip to the impeller on the performance of regenerative blower.

Theoretically and numerically, many researchers studied the effect of different blade angels or blade shape on the performance of regenerative blower and pump by using CFD analysis. The previous CFD analysis [4]-[10] showed a helical internal flow pattern in regenerative turbo-machines and that the flow passes through the blade several times via the impeller. Of these researchers Meakhail and Park [10] using CFD analysis, they showed that the flow enters the impeller from the blade side (about $65 \%$ of the blade side area) and leaves from the blade tip and blade side (the remaining 35\% from the blade side area) as shown in Figure 1. Depending upon this observation, Meakhail and Park [10] proposed a mathematical model which handles one inlet angle and two exit angles for the impeller blades of regenerative pump (for incompressible flow). The authors modified this mathematical model to be more convenient in case of using regenerative blower to be investigated experimentally and numerically by using CFX-ANSYS 16.1 software.

Therefore, a regenerative blower system is designed in the present study such that four impellers with different inlet flow angles $\left(90^{\circ}, 115^{\circ}, 125^{\circ}\right.$, and $\left.135^{\circ}\right)$ are manufactured as shown in Figure 2. The validation of the theoretical and numerical investigations with the experimental results of the effect of inlet blade angle on the performance of regenerative blowers is achieved.

\section{Theoretical Models}

The elements of the regenerative blower, as shown in Figure 3, are an impeller, inlet port, outlet port, stripper, 


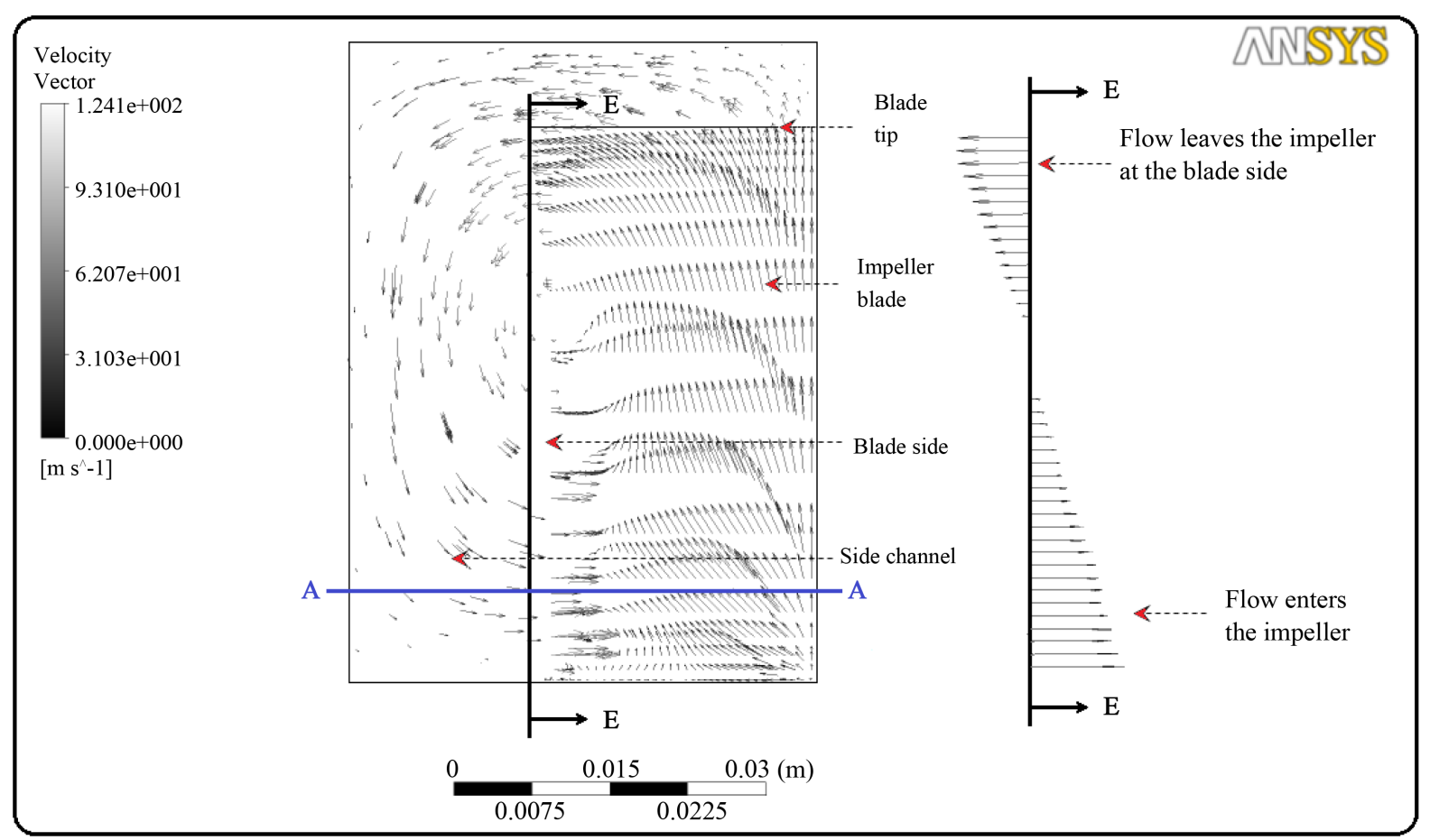

Figure 1. Velocity vectors at section on the middle between two blades of the blower impeller.

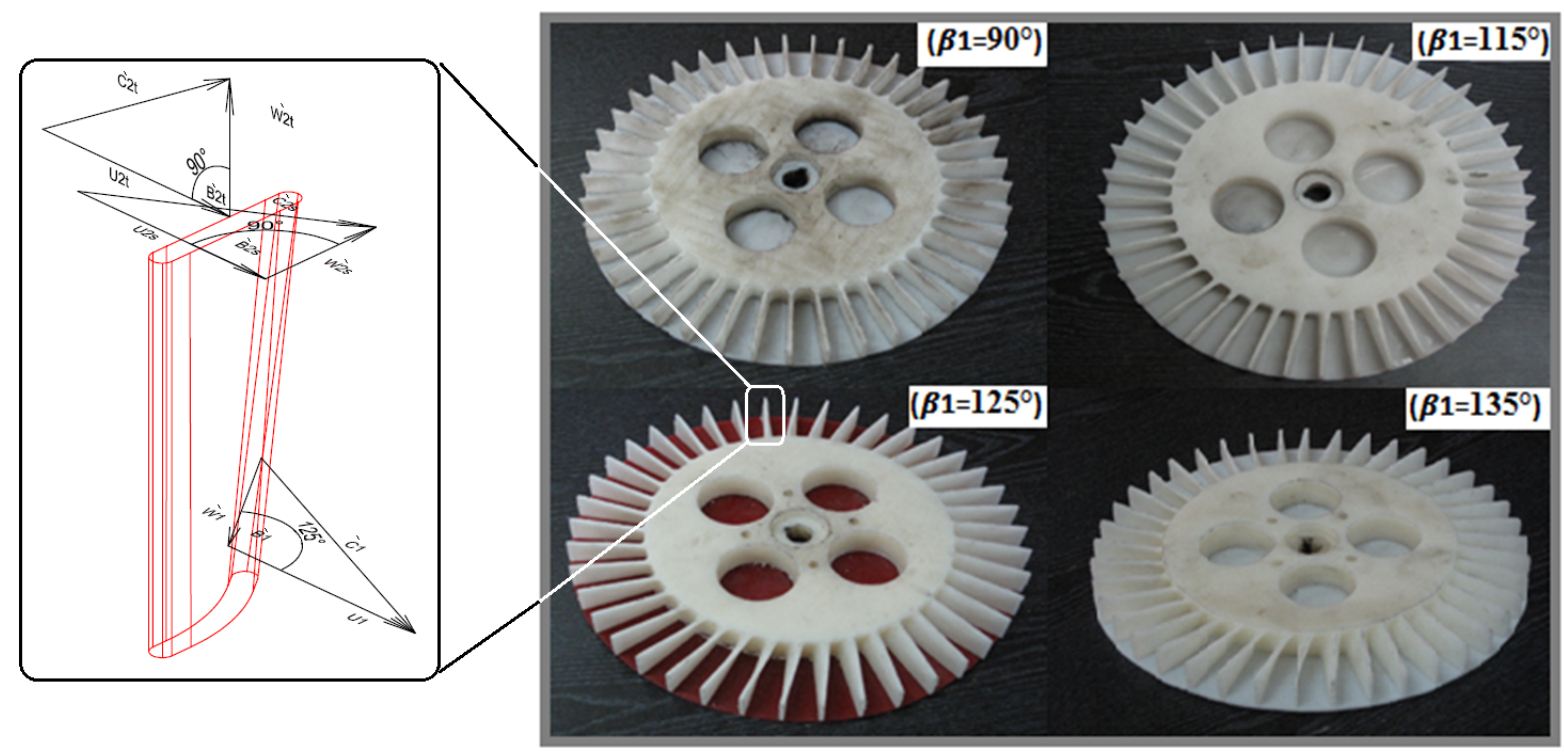

Figure 2. A photograph of manufactured impellers with schematic diagram of the inlet blade angle of $125^{\circ}$.

side channel and a casing. The impeller has blades machined into one side at its periphery and cambered from meddle by different angles. This produces a series of helical flows rotations, returning the fluid repeatedly through the blades with additional energy as it passes through an open channel.

For the mathematical formulation, the geometry of the impeller and side channel with main dimensions of the tested blower is specified in Figure 4. The geometrical characteristics can be defined by means of the following parameters:

- outer radius of the side channel, $r_{c}$

- conventional inlet mean radii of the meridian flow stream at the impeller, $r_{1}$ 


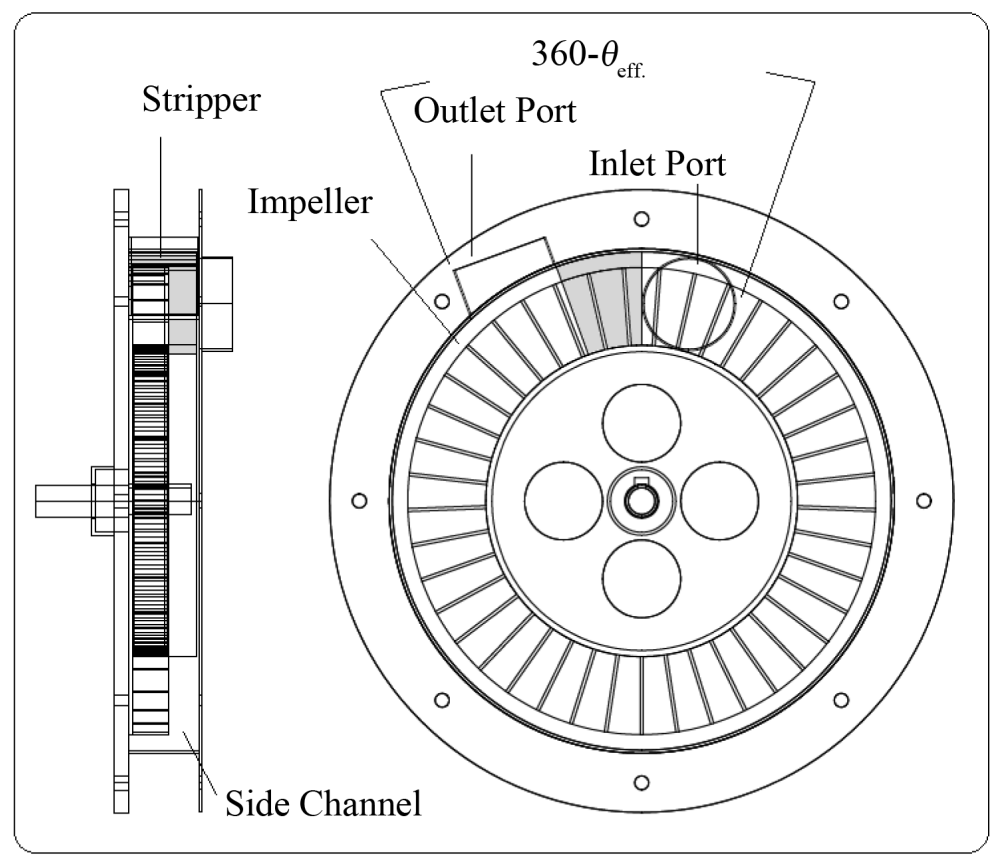

Figure 3. Schematic diagram of regenerative blower.

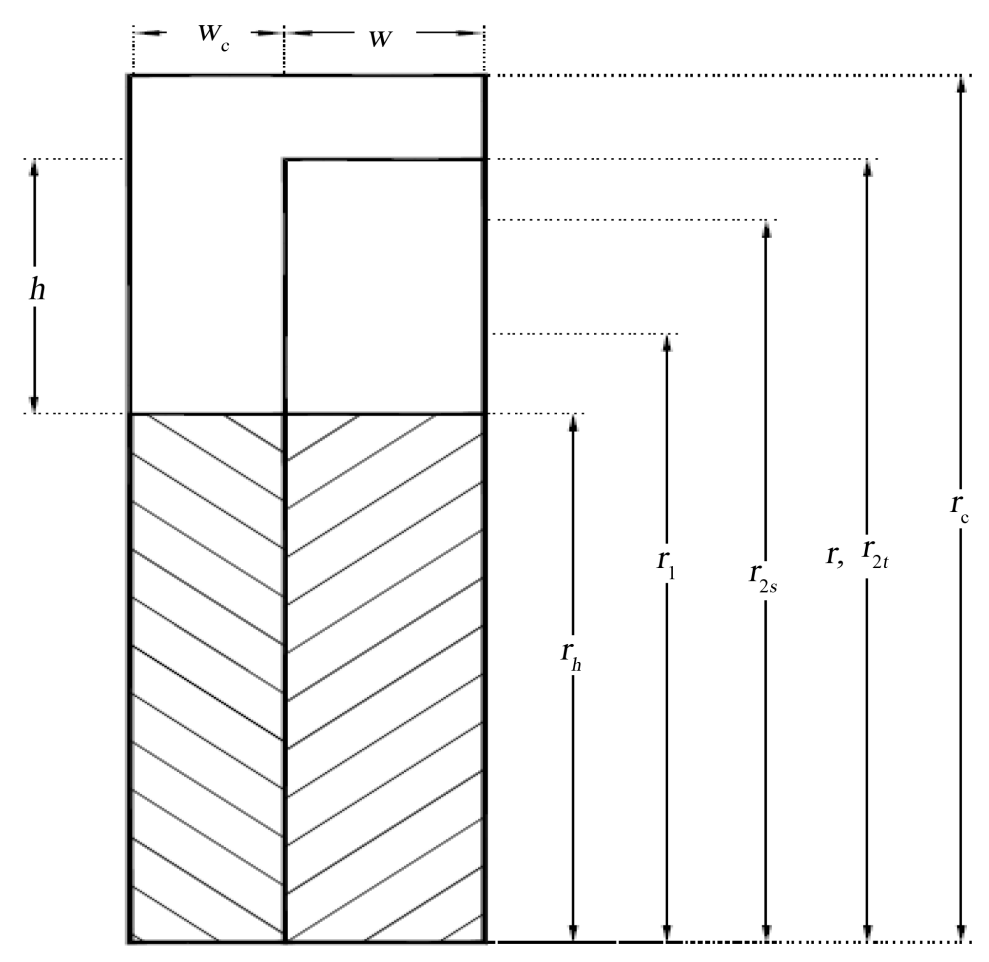

Figure 4. Impeller and side channel flow path and their geometry.

- height of the vanes, $h$

- axial width of the vanes, $w$

- axial width of the side channel, $w_{c}$

- hub radius of the impeller, $r_{h}$

- outlet mean radius of the meridian flow stream at the impeller tip, $r_{2 t}$ 
- outlet mean radius of the meridian flow stream at the impeller side, $r_{2 s}$

where $r_{h}=100 \mathrm{~mm}, r_{2 t}=150 \mathrm{~mm}, r_{c}=160 \mathrm{~mm}, h=50 \mathrm{~mm}, w_{c}=20 \mathrm{~mm}$ and $w=25 \mathrm{~mm}$. Several radii in Figure 4 are defined as:

$$
\begin{gathered}
R_{m}=\sqrt{\frac{\left(R_{2 t}^{2}+R_{h}^{2}\right)}{2}} \\
R_{1}=\frac{R_{m}+R_{h}}{2} \\
R_{2 s}=\frac{R_{m}+R_{2 t}}{2}
\end{gathered}
$$

where $R_{h}$ is hub radius and $R_{2 t}$ is the tip radius of the impeller.

In order to receive further information about quantitative influence of geometrical parameters on the regenerative blower performance a one-dimensional model has been formatted. The measured blower performance characteristics are expressed with dimensionless flow coefficient $\varphi$ and the head coefficient $\psi$ defined by the following Equations (1) and (2) Choi et al., [11].

$$
\begin{gathered}
\psi=\frac{\frac{\Delta p}{\rho}}{\frac{u^{2}}{2}} \\
\varphi=\frac{Q}{u A_{c}} \\
A_{c}=w c(r c-r h)+w(r c-(h+r h))
\end{gathered}
$$

Applying the angular momentum equation per one circulation to the fluid in the side channel that is subjected to torque transmitted by the impeller, the expression for the head rise of the blower per one circulation, $h_{/ c i r}$, can be written as; Meakhail and Park [10]:

$$
g h_{\text {/cir }}=\frac{A_{2 t} C_{m 2 t} r_{2 t} C_{u 2 t}+A_{2 s} C_{m 2 s} r_{2 s} C_{u 2 s}-A_{1} C_{m 1} r_{1} C_{u 1}}{r_{m} A_{c}}
$$

where $A_{s}$ are the areas and defined as:

$$
\begin{gathered}
A_{1}=\pi\left(\frac{r_{m}^{2}-r_{h}^{2}}{z}\right) \\
A_{2 s}=\pi\left(\frac{r_{2 t}^{2}-r_{m}^{2}}{z}\right) \\
A_{2 t}=\frac{2 \pi r_{2 t} w}{z}
\end{gathered}
$$

The total head of the blower and the head coefficient can be expressed as

$$
H=n h_{\text {lcir }}-\frac{1}{2 g} K_{P}\left(\frac{Q}{A_{C}}\right)^{2}
$$

$K_{p}$ is the loss coefficient related to the friction forces on the side channel wall and is assumed to be equal to $0.01[10]$.

where the number of circulation $\mathrm{n}$ can be simply calculated from

$$
n=\frac{\theta_{\text {eff. }}}{360} z
$$

where $\theta_{\text {eff. }}$ is the effective angle of the blower from the inlet port to the outlet port. 
Equation (7) is the same equation obtained by Wilson et al., [12] and Badami [13] but it differs in containing the term $\left(A_{2 s} C_{m 2 s} r_{2 s} C_{u 2 s}\right)$, which represents the momentum of the fluid leaving at the side of the impeller blade as well as the number of circulation. This term is a function of the side exit angle of the impeller since $C_{u 2 s}$ is given by:

$$
\begin{gathered}
C_{u 2 s}=\sigma_{s}\left(u_{2 s}-C_{m 2 s}\left(-\cot \left(180-\beta_{2 s}^{\prime}\right)\right)\right)=u_{2 s}-C_{m 2 s}\left(-\cot \left(180-\beta_{2 s}\right)\right) \\
C_{u 2 t}=\sigma_{t}\left(u_{2 t}-C_{m 2 t}\left(-\cot \left(180-\beta_{2 t}^{\prime}\right)\right)\right)=u_{2 t}-C_{m 2 t}\left(-\cot \left(180-\beta_{2 t}\right)\right)
\end{gathered}
$$

where $\beta_{2 s}^{\prime}$ and $\beta_{2 t}^{\prime}$ are the blade exit angles at the blade side and blade tip, respectively, as in Figure 5, and the slip factor at the tip and side is calculated by:

$$
\sigma_{s}=\frac{1}{\left\{1+2.5\left[1+\sin \left(\beta_{2 s}^{\prime}+90\right)\right] / z\right\}} \text { and } \sigma_{t}=\frac{1}{\left\{1+2.5\left[1+\sin \left(\beta_{2 t}^{\prime}+90\right)\right] / z\right\}}
$$

Under the hypothesis of constant angular speed of the fluid in the side channel, the kinetic ratio $\frac{C u_{1}}{u}$ can be calculated by means of the following equation [14]:

$$
\frac{C u_{1}}{u}=\frac{r_{1}}{r_{C}} \varphi
$$

The circulatory velocity at the tip and side $\left(C_{m 2 t}\right.$ and $\left.C_{m 2 s}\right)$ calculated as:

$$
\begin{gathered}
\frac{\xi_{i}}{2 \sin ^{2} \beta_{2 t}}\left(C_{m 2 t}\right)^{2}+C_{m 2 t} \sigma_{t}\left(u_{2 t}+u_{1}\right)\left(-\cot \left(180-\beta_{2 t}\right)\right) \\
+\frac{\xi_{c}}{2}\left(\frac{Q}{A_{c}}\right)^{2}+2 u_{1} \frac{Q}{A_{c}}-\sigma_{t}\left(u_{2 t}+u_{1}\right) u_{2 t}=0 \\
\frac{\xi_{i}}{2 \sin ^{2} \beta_{2 s}}\left(C_{m 2 s}\right)^{2}+C_{m 2 t} \sigma_{s}\left(u_{2 s}\right)\left(-\cot \left(180-\beta_{2 s}\right)\right)+\frac{\xi_{c}}{2}\left(\frac{Q}{A_{c}}\right)^{2}+u_{1} C_{u 1}-\sigma_{s} u_{2 s}^{2}=0
\end{gathered}
$$

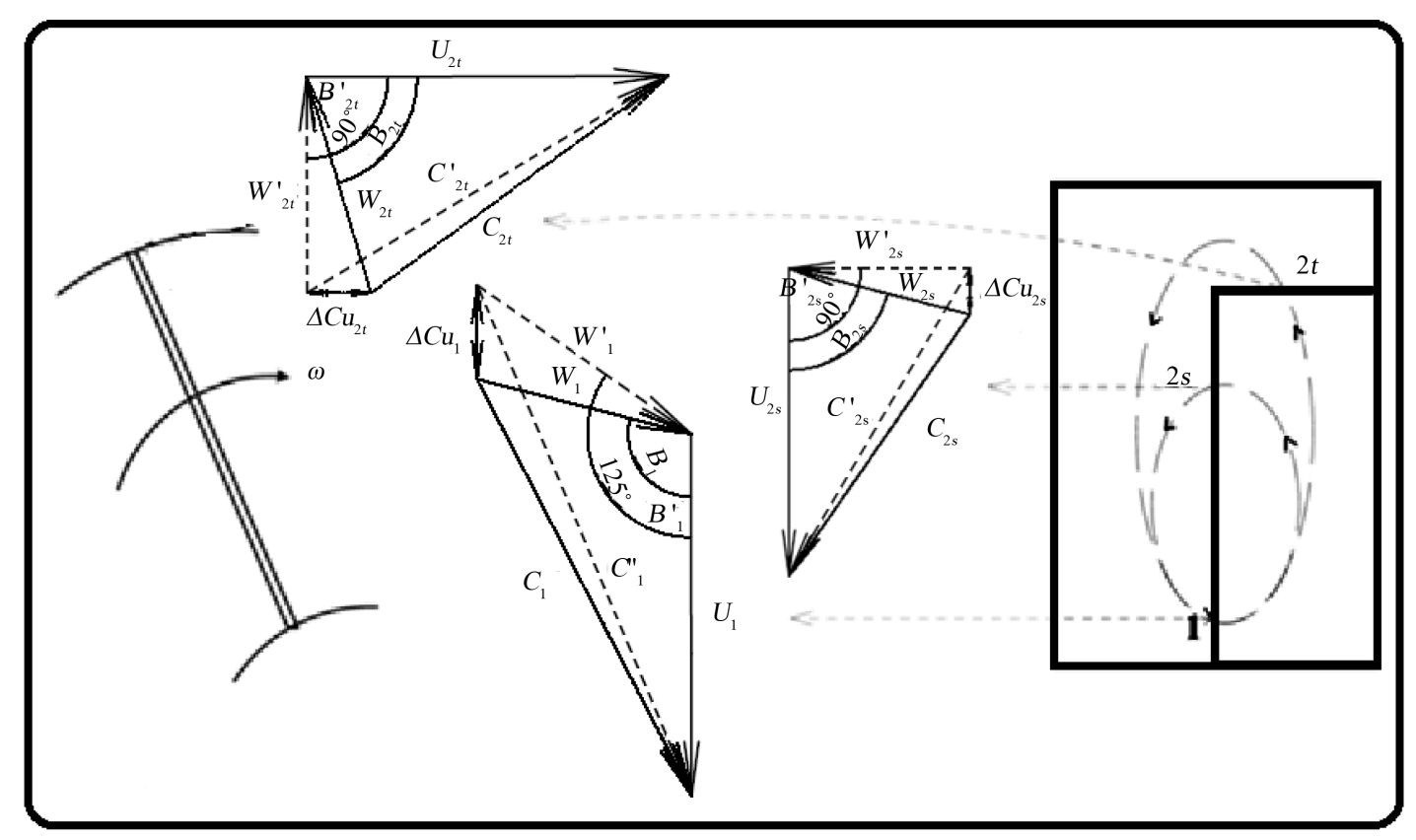

Figure 5. Diagram of the velocity triangles. 
where $\xi_{i}$ is the loss coefficient and is evaluated experimentally [13] and ranged between 0.0042 and 0.0063 for all impeller blades.

$\xi_{c}$ is the channel skin friction loss and calculated as in [10] and it is equal to 0.011 for the rotational speed of $3000 \mathrm{rpm}$.

The inlet circulatory flow rate, $Q_{m 1}$ can be calculated by the continuity equation as:

$$
Q_{m 1}=Q_{m 2 s}+Q_{m 2 t}
$$

The efficiency of the regenerative blower is the ratio between the hydraulic power transferred to the working fluid and the power introduced into the system by the impeller [14] and is estimated using the equation:

$$
\eta=\frac{r_{2 t}}{r_{c}} \frac{\varphi_{R} \psi}{\psi+K_{p} \varphi^{2}}
$$

where $\varphi_{R}$ is real dimensionless flow rate coefficient and calculated as in [14].

\section{Experimental Analysis}

In the present experimental study, a regenerative blower system with impellers of different inlet blade angles of $90^{\circ}, 115^{\circ}, 125^{\circ}$ and $135^{\circ}$ is designed and manufactured by using CNC 3D Machine as shown in Figure 2 and Figure 3. The experimental work is carried out by two steps. The first step is studying the effect of inlet blade angle of $90^{\circ}$ and analyzing the results by using the CFD analysis. The CFD analysis shows shock losses and vortices behind each blade at the inlet flow regions. To reduce these losses, the inlet blade angle should be increased in range between $25^{\circ}$ and $45^{\circ}$. The second step is splitting this angle range to three inlet selected blade angles of $115^{\circ}, 125^{\circ}$ and $135^{\circ}$ according to the comparison of the experimental work with the CFD results. The CFD analysis for these angels shows the disappearance of these shock losses and vortices that are formed behind the blade of angle $90^{\circ}$, and the appearance of air vortices and circulations at the same time. Figure 6 shows the scheme of a regenerative blower that consists of an impeller with radial blade (c) and a casing (j) with bearing (k) where the side channel (d) is machined. There is a stripper block (b) to separate the inlet port (a) and outlet ports (e) that's connected by the air flow rate control valve (f) and calibrated air velocity measuring instrument (g). This blower is driven by $1 \mathrm{hp} .3$ phase induction motor $(\mathrm{h})$ in which the motor rotor is coupled with the blower

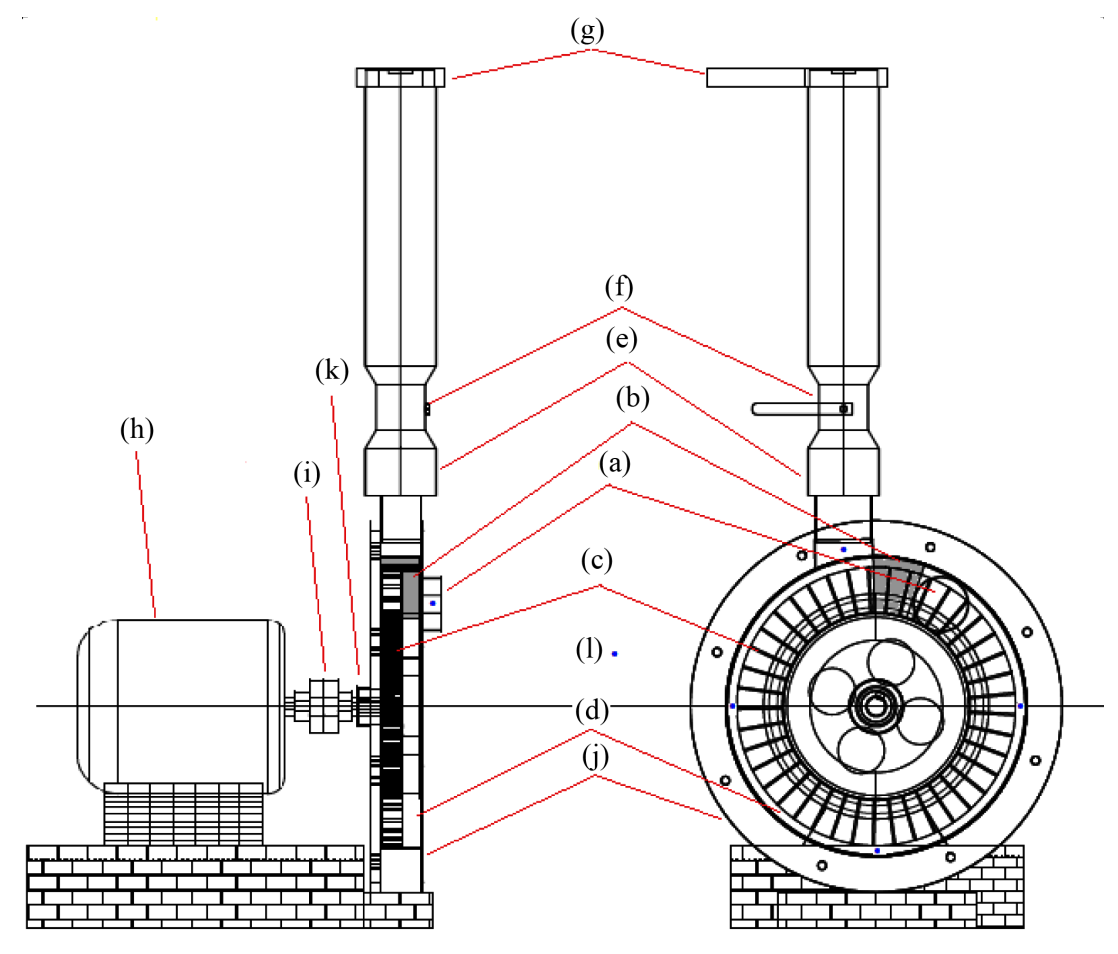

Figure 6. Schematic diagram of a regenerative blower. 
rotor by a coupling (i). The impellers have blades of diameter $300 \mathrm{~mm}$, height $50 \mathrm{~mm}$, width $23 \mathrm{~mm}$ and thickness $3 \mathrm{~mm}$. The experimental work is carried out at a rotational speed of $3000 \mathrm{rpm}$ and at eight different outlet flow rates which is expressed as dimensionless flow coefficient $\varphi$ and varied from 0 to 0.7 . The blower rotational speed is measured by digital tachometer, and controlled by changing the feeding electrical frequency to the induction motor that drives the blower by using adjustable frequency driver. The pressures at inlet, outlet, and around the circumference of impeller, denoted by small dots at locations (1), are measured at different flow rates by a digital manometer with accuracy of $\pm 0.25 \%$ of full scale, including the combined effects of temperature, linearity, repeatability, hysteresis and resolution. The accuracy of the Thermo-Anometer air velocity meter unit is $\pm(3 \%+1$ digit $)$. The rotational velocity is monitored using a digital tachometer whose accuracy falls within $\pm(0.5 \%+1$ digit $)$. The scattered data are evaluated from repeatability tests and sensitivity analyses. Thus, the estimated percentages of the errors in the efficiency, flow coefficient and head coefficient from the experiments are $\pm 4.5 \%, \pm 10.5 \%$ and $\pm 1.3 \%$, respectively.

\section{Results}

The obtained results of the blower performance and efficiency are subdivided into three parts, the first part presents the experimental result of different inlet blade angles, the second part presents CFD results, and finally the third part presents the comparison of experiment with 1-D model and CFD results.

\subsection{Experimental Results}

The experimental characteristic curves for the four impellers with inlet blade angles of $90^{\circ}, 115^{\circ}, 125^{\circ}$ and $135^{\circ}$ are shown in Figure 7. It can be observed that, the compression increases as the losses behind the blades decreases. This leads to the improvement of the regenerative blower performance and efficiency. So the impeller of inlet blade angle of $125^{\circ}$ has a better efficiency than the other impellers with inlet flow angles $\left(90^{\circ}, 115^{\circ}\right.$ and $135^{\circ}$ ). The efficiency is generally low at lower flow rates and it increases as the flow rate through the blower increases [15]. This is another characteristic of the regenerative blower, which suggests that in order to obtain a good efficiency; the blower should be operated at a higher flow rate. The reason for low efficiency at a low flow rate is due to greater circulatory power, the increased number of circulations at the low flow rates, causes the increase of both circulatory head loss and shock loss. When the flow rate increases through the blower, there will be fewer vortices circulations, which mean better efficiency [15]. The change of inlet blade angles leads to redirection of the inlet flow to the impeller, which leads to the increase of the transferred energy from impeller blade to the flow inside the channel and leads in turn to the improvement of the blower performance and efficiency. Figure 8 shows the relation between the inlet blade angle and maximum efficiencies at the maximum flow rate (at dimensionless flow coefficient of 0.7). The maximum efficiencies were found to be 47.72, 45.59, 44.69, and $43.59 \%$ for impellers of inlet blades angles $125^{\circ}, 135^{\circ}, 90^{\circ}$, and $115^{\circ}$ respectively.

\subsection{CFD Results}

A CFD simulation is carried out by using ANSYS 16.1 software, in order to increase the knowledge of the flow field inside the regenerative blower and to analyze the velocity vectors around the impeller. The steady state conditions are considered in the simulation and a compressible air ideal gas with constant specific heat is assumed. The standard $\mathrm{k}-\varepsilon$ model has been tailored specifically for recirculating flows Lettieri et al., [16], so turbulence is modeled using the standard k- $\varepsilon$ turbulence model Fan et al., [17], the energy equation is solved additionally and all the walls are considered as adiabatic and smooth. The mass flow rate normal to the boundary is set at the inlet duct as boundary conditions, while the total pressure and temperature obtained from the experiments are imposed at the outlet. Some of the main characteristics of the fluid at the boundary conditions are summarized in Table 1.

An investigation of grid independence is carried out to check for the proper mesh. For impeller of inlet blade angle of $125^{\circ}$, as an example, four different grids are checked (456,324 cells, 580,560 cells, 628,023 cells, and $1,889,641$ cells). The maximum value of the pressure difference between inlet and outlet occurs at grid No.4 $(1,889,641$ cells $)$ which is greater than the value of the designed pressure difference at gridno. $3(628,023$ cells $)$ by a small difference of $4.8 \%$. This indicates that both of the two grids are approaching grid independence. All 


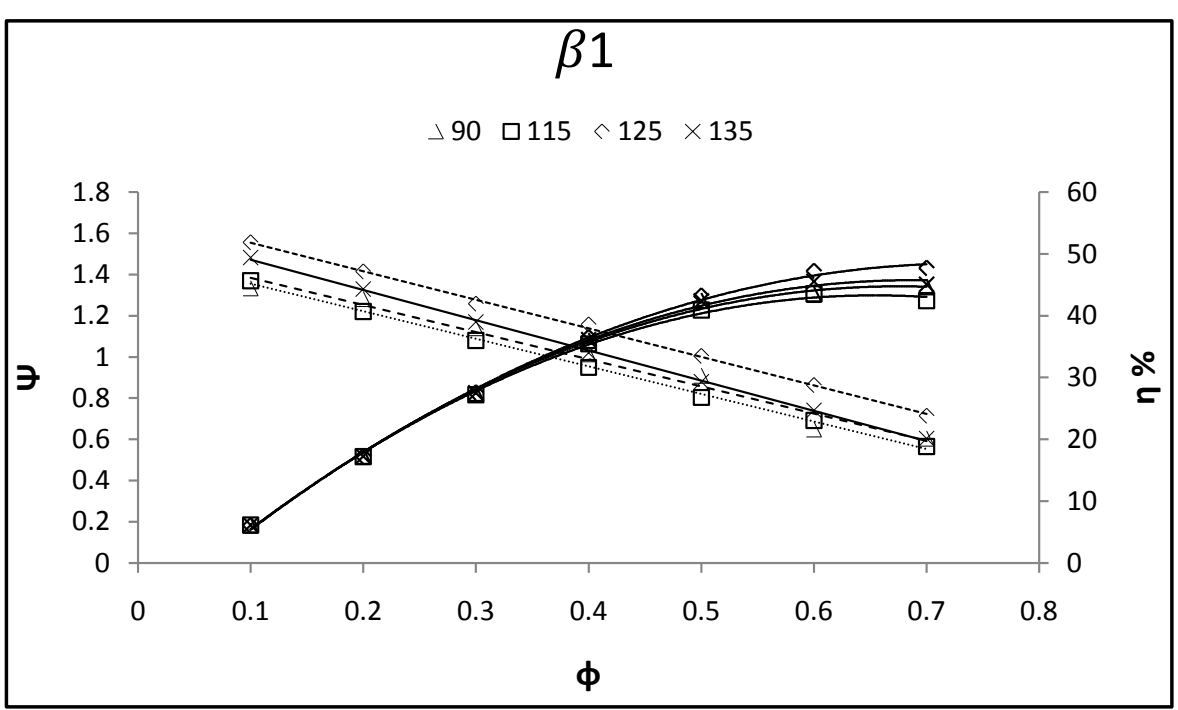

Figure 7. Blower characteristic and efficiency curves for different inlet blade angles.

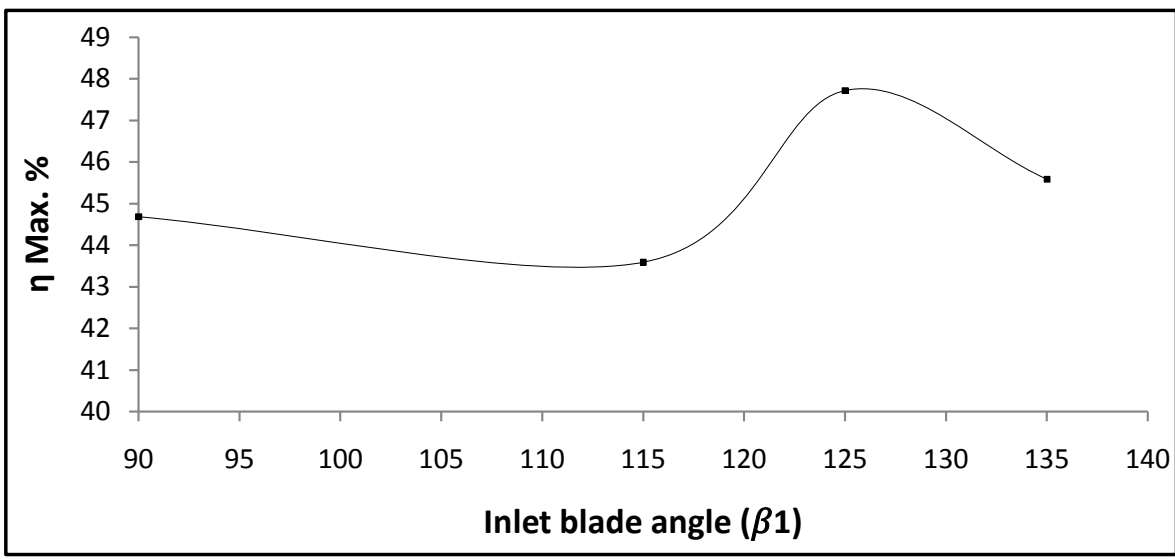

Figure 8. Blower maximum efficiency for different inlet blade angles.

Table 1. The main characteristics of the fluid at the boundary conditions.

\begin{tabular}{|c|c|c|c|c|c|c|c|c|c|}
\hline \multirow{3}{*}{ No. } & \multirow{3}{*}{$\begin{array}{c}\text { Impeller } \\
\text { Type }\end{array}$} & \multicolumn{8}{|c|}{ Flow Coefficient, $(\varphi)$} \\
\hline & & \multicolumn{2}{|c|}{0.1} & \multicolumn{2}{|c|}{0.3} & \multicolumn{2}{|c|}{0.5} & \multicolumn{2}{|c|}{0.7} \\
\hline & & $\begin{array}{c}\dot{m}_{i n} \\
\mathrm{~kg} / \mathrm{s}\end{array}$ & $\begin{array}{l}P_{\text {Out }} \\
\mathrm{kPa}\end{array}$ & $\begin{array}{c}\dot{m}_{i n} \\
\mathrm{~kg} / \mathrm{s}\end{array}$ & $\begin{array}{l}P_{\text {out }} \\
\mathrm{kPa}\end{array}$ & $\begin{array}{c}\dot{m}_{i n} \\
\mathrm{~kg} / \mathrm{s}\end{array}$ & $\begin{array}{l}P_{\text {Out }} \\
\mathrm{kPa}\end{array}$ & $\begin{array}{c}\dot{m}_{i n} \\
\mathrm{~kg} / \mathrm{s}\end{array}$ & $\begin{array}{l}P_{\text {Out }} \\
\mathrm{kPa}\end{array}$ \\
\hline 1 & $90^{\circ}$ & $8.1 \mathrm{E}-3$ & 1.73 & $24.31 \mathrm{E}-3$ & 1.45 & $40.52 \mathrm{E}-3$ & 1.12 & $56.73 \mathrm{E}-3$ & 0.7 \\
\hline 2 & $115^{\circ}$ & $8.1 \mathrm{E}-3$ & 1.79 & $24.31 \mathrm{E}-3$ & 1.37 & $40.52 \mathrm{E}-3$ & 0.98 & $56.73 \mathrm{E}-3$ & 0.62 \\
\hline 3 & $125^{\circ}$ & $8.1 \mathrm{E}-3$ & 2.01 & $24.31 \mathrm{E}-3$ & 1.6 & $40.52 \mathrm{E}-3$ & 1.25 & $56.73 \mathrm{E}-3$ & 0.82 \\
\hline 4 & $135^{\circ}$ & $8.1 \mathrm{E}-3$ & 1.91 & $24.31 \mathrm{E}-3$ & 1.48 & $40.52 \mathrm{E}-3$ & 1.08 & $56.73 \mathrm{E}-3$ & 0.69 \\
\hline
\end{tabular}

results in the following discussions are done for grid No. 3 case.

The regenerative blower operation is affected by different types of losses [18]. On designing the regenerative blower, it is important to take into account how to minimize the losses as possible in order to improve its efficiency [19]. So, these losses and their impact on the performance of each impeller should be well studied. Shock losses, vortices and flow circulations, as examples, appear in the CFD velocity vectors behind each blade at the 
blade inlet flow area. Figure 9 shows the velocity vectors at the blade inlet flow area for different inlet flow angles. The shock losses and vortices appear at the inlet flow region behind each blade of the impeller of inlet angle of $90^{\circ}$. Air vortices losses and flow circulations areas appear at inlet flow angles of $115^{\circ}, 125^{\circ}$ and $135^{\circ}$ and vary from inlet angle to another. The energy losses between each blade increase as the area of losses increases, which leads to the decrease of the blower output pressure, performance and efficiency. These results agree well with that obtained experimentally. At outlet flow regions, the CFD analysis show small and unremarkable losses at the outlet flow angle of $90^{\circ}$ as shown in Figure 10, thus, it is not needed to modify this angle.
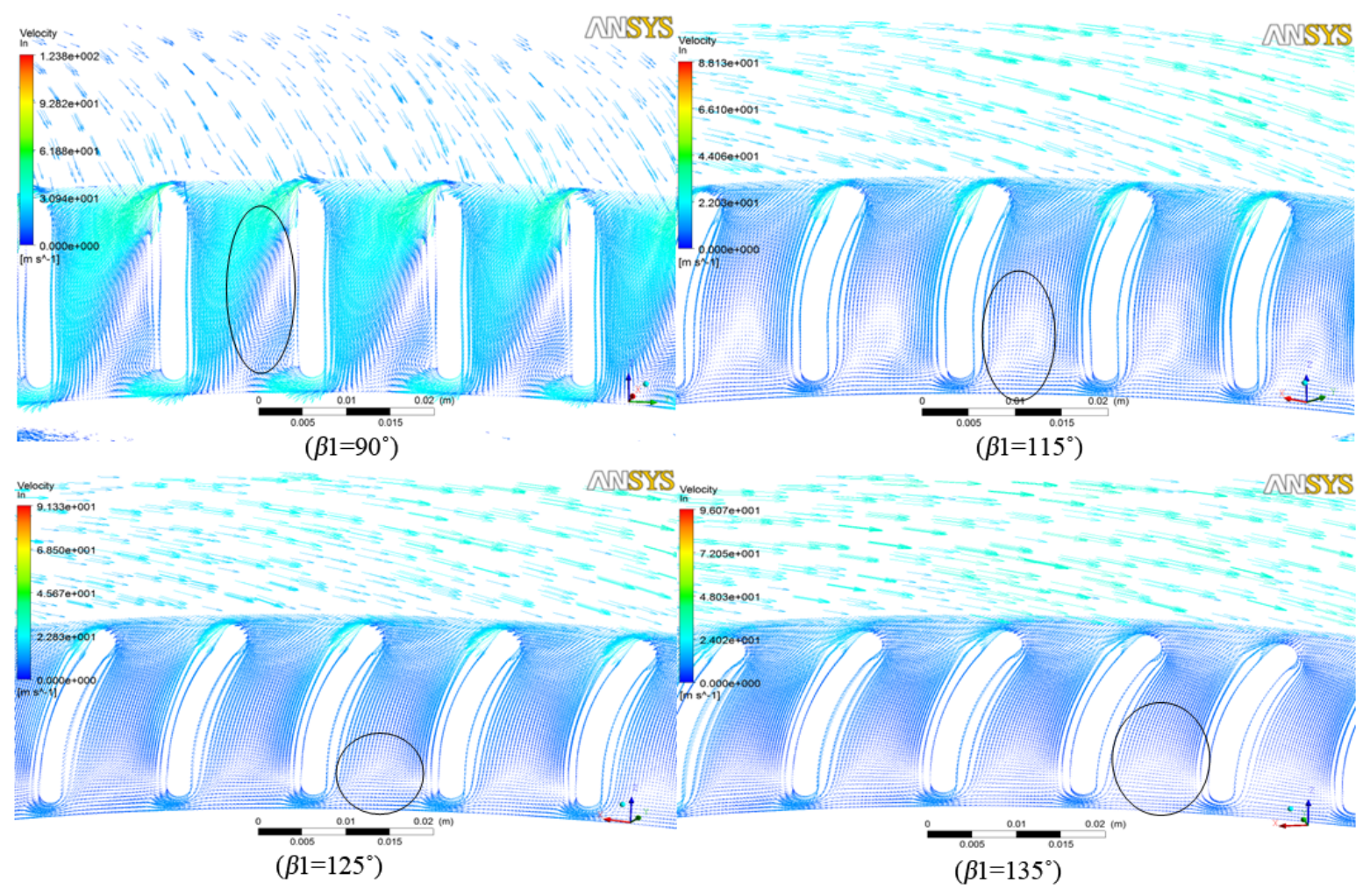

Figure 9. The velocity distribution of the inlet flow to the impeller for different inlet blade angles.

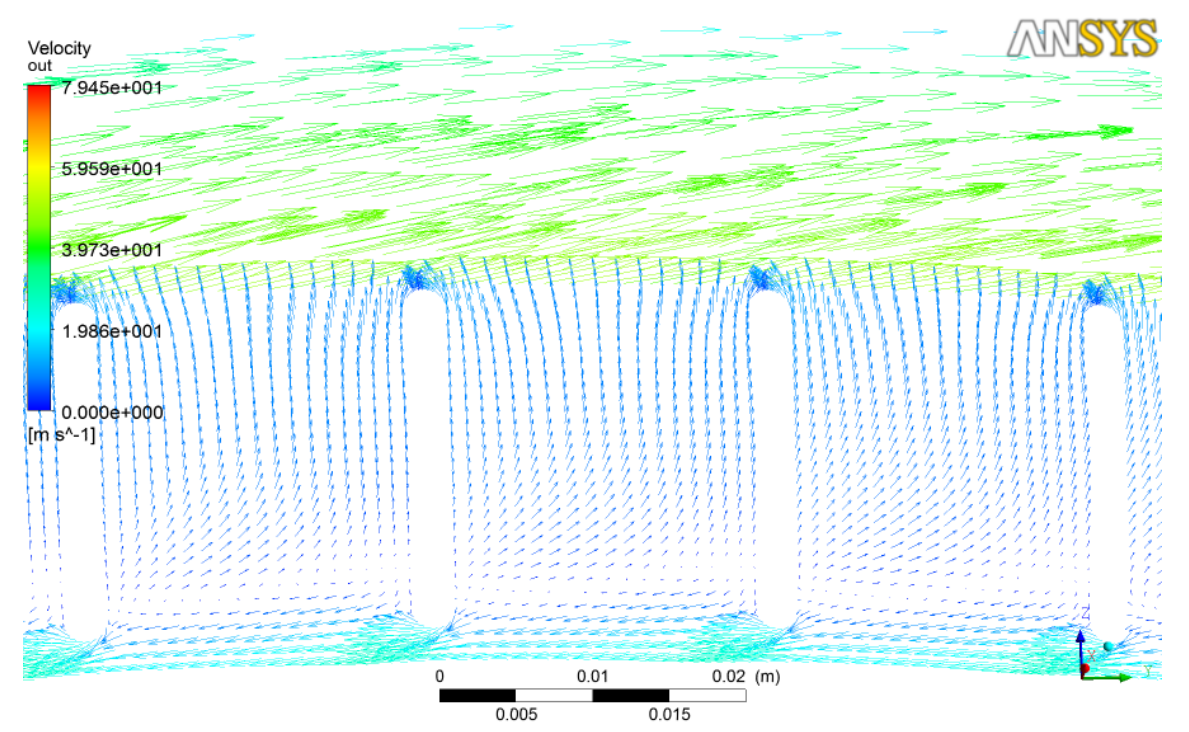

Figure 10. The velocity distribution of the outlet flow to the impeller for outlet blade angles of $90^{\circ}$. 


\subsection{Comparing the Experiment with 1-D Model, and CFD Results}

A verification of the experimental with numerical results from one dimensional model and CFD results is carried out by quantitative comparison. Figure 11 and Figure 12 show the comparison of performance and efficiency between the experimental and one-dimensional model with CFD results for different inlet blade angles. The theoretical one-dimensional model is more compatible and closer to the experimental results. Some differences arise between CFD and the experimental results due to three reasons. Firstly, the gaps leakage that have only partially taken into account on the CFD calculation; this leakage is proportional to the pressure difference between inlet and outlet [7]. A second reason for the difference between CFD and experimental results is the flow inside the regenerative blower that is actually unsteady and the CFD simulations are computed as steady state flow. A third reason is that the blower walls are considered smooth in the CFD simulation, however, different unknown surface roughness exist due to some defects in manufacture. The final reason is the standard $\mathrm{k}$ - $\varepsilon$ turbulence model, which is used in the CFD simulation caused some deviations in case of forced flow, which appear clearly in Figure 11 for the impellers of inlet blade angles of $115^{\circ}$ and $135^{\circ}$. The proposed mathematical model has a good agreement with the experimental results with accuracy ranging from $86 \%$ to $99.7 \%$. The theoretical and CFD results shown in Figure 11 and Figure 12 are all converged to the experimental results for most cases. At the flow rate of $32.42 \mathrm{E}-3 \mathrm{~kg} / \mathrm{s} \quad(\varphi=0.4)$ the theoretical one-dimensional model performance match the experimental performance at different inlet blade angles. The design and the best efficiency case occur for this blower at the flow rate between $48.62 \mathrm{E}-3 \mathrm{~kg} / \mathrm{s}$ and $56.73 \mathrm{E}-3 \mathrm{~kg} / \mathrm{s}$ (at $\varphi$ between 0.6 and 0.7 ) and with different inlet blade angles.

\section{Conclusions}

This study focuses on investigating a theoretical one-dimensional mathematical model by the experiments and studying the effect of inlet flow angle on the performance of regenerative blower. The experimental results
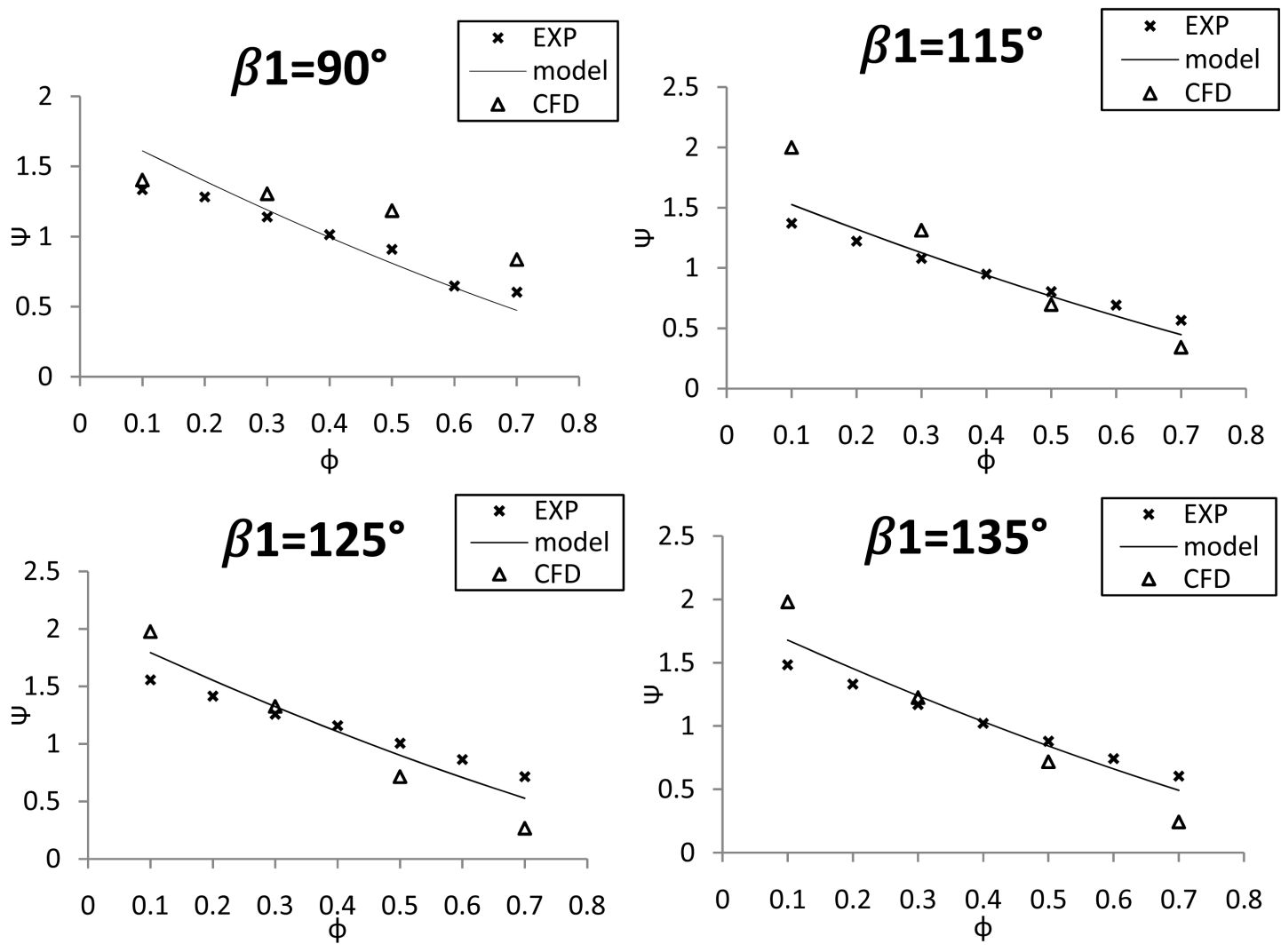

Figure 11. Comparison of performance curves of the regenerative blower different inlet blade angles between theoretical 1-D models, experimental and CFD. 


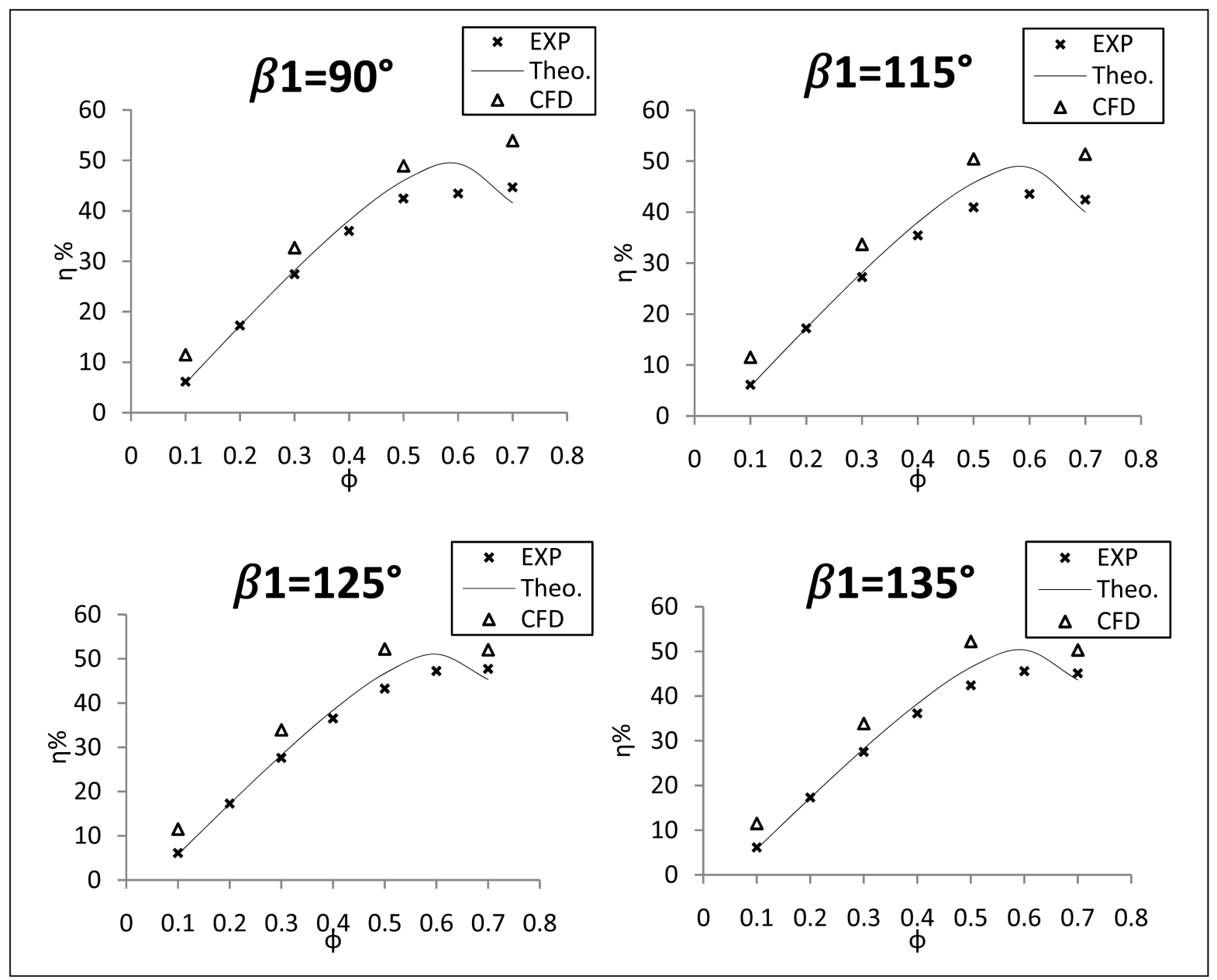

Figure 12. Comparison of efficiencies curves of the regenerative blower for different inlet blade angles between theoretical, experimental and CFD.

showed that the pressure head and the efficiency depend strongly on the blade inlet flow angles as well as on the blade geometry. The simulation of the whole blower is performed using CFX-ANSYS 16.1. The results also show that the best blower performance is obtained at the inlet flow angle of $125^{\circ}$. The relative velocity vectors at the inlet flow region around the blade, which is obtained from the CFD simulation of inlet flow angle of $125^{\circ}$, shows smaller area of vortices and flow circulations than the other studied inlet flow angles.

This work proves that on designing the regenerative blower, the effect of inlet flow angle to the impeller should be taken into account. These angles were proven to have a major effect on redirection of the flow to the impeller, and leads in turn to an ideal use of the working fluid energy. The losses in energy are reduced such that the efficiency increases. The study shows a good improvement in efficiency with a range of 3\% - 4.1\%. Finally, the proposed theoretical one-dimensional mathematical model and CFD analysis yield results that are in good agreements with the experimental results.

\section{References}

[1] Tomita, Y., Yamazaki, S. and Sasahara, T. (1973) The Scale Effect and Design Method of the Regenerative Pump with Non-Radial Vanes. Bulletin of the JSME, 16, 1176-1183. http://dx.doi.org/10.1299/jsme1958.16.1176

[2] Hübel, M., Blättel, B. and Strohl, W. (1995) Investigation on Fluid Mechanics of the Regenerative Pump Used in Gasoline Injection Systems. SAE Technical Paper, 131-139.

[3] Badami, M. (1997) Theoretical and Experimental Analysis of Traditional and New Periphery Pumps. SAE Technical Paper, 45-55. 
[4] Choil, W.C., Yoo, I.S., Park, M.R. and Chung, M.K. (2013) Experimental Study on the Effect of Blade Angle on Regenerative Pump Performance. Journal of Power and Energy, 227, 585-592. http://dx.doi.org/10.1177/0957650913487731

[5] Lee, K.-Y., Choi, Y.-S. and Jeong, K.-H. (2010) Design of Side Channel Type Regenerative Blower. AIP Conference Proceedings, 1225, 704.

[6] Izenson, M.G., Chen, W.B., Hill, R.W., Phillips, S.D. and Paul, H.L. (2011) Design and Development of a Regenerative Blower for EVA Suit Ventilation. 41 st International Conference on Environmental Systems, Portland.

[7] Weise, V. and Beilke, J. (1998) 3D Flow in a Peripheral Fan. International Journal of Computer Applications in Technology, 11, 203-210.

[8] Badami, M. and Mura, M. (2012) Comparison between 3D and 1D Simulations of a Regenerative Blower for Fuel Cell Applications. Energy Conversion Management, 55, 93-100. http://dx.doi.org/10.1016/j.enconman.2011.10.003

[9] Quail, F.J., Scanlon, T. and Baumgartner, A. (2012) Design Study of a Regenerative Pump Using One-Dimensional and Three-Dimensional Numerical Techniques. European Journal of Mechanics B/Fluids, 31, 181-187. http://dx.doi.org/10.1016/j.euromechflu.2011.06.003

[10] Meakhail, T. and Park, S.O. (2005) An Improved Theory for Regenerative Pump Performance. Proceedings of the Institution of Mechanical Engineers, Part A: Journal of Power and Energy, 219, 213-222. http://dx.doi.org/10.1243/095765005X7565

[11] Choi, W.C., Yoo, I.S., Park, M.R. and Chung, M.K. (2013) Experimental Study on the Effect of Blade Angle on Regenerative Pump Performance. Journal of Power and Energy, 227, 585-592. http://dx.doi.org/10.1177/0957650913487731

[12] Wilson, W.A., Santalo, M.A. and Oelrich, J.A. (1955) Theory of the Fluid-Dynamic Mechanism of Regenerative Pumps. Trans ASME, 77, 1303-1316.

[13] Badami, M. (1997) Theoretical and Experimental Analysis of Traditional and New Periphery Pumps. SAE Technical Paper Series, No. 971074, 45-55. http://dx.doi.org/10.4271/971074

[14] Badami, M. and Mura, M. (2010) Theoretical Model with Experimental Validation of a Regenerative Blower for Hydrogen Recirculation in a PEM Fuel Cell System. Energy Conversion Management, 51, 553-560. http://dx.doi.org/10.1016/j.enconman.2009.10.022

[15] Song, J.W., Engeda, A. and Chung, M.K. (2003) A Modified Theory for the Flow Mechanism in a Regenerative Flow Pump. Proceedings of the Institution of Mechanical Engineers, Part A: Journal of Power and Energy, 217, 311-322. http://dx.doi.org/10.1243/095765003322066538

[16] Lettieri, G.-L., Dodge, A., Boer, G., de Rooij, N.F. and Verpoorte, E. (2003) A Novel Microfluidic Concept for Bioanalysis Using Freely Moving Beads Trapped in Recirculating Flows. Lab on a Chip, 3, 34-39. http://dx.doi.org/10.1039/b211869f

[17] Fan, J., Eves, J., Thompson, H.M., Toropov, V.V., Kapur, N., Copley, D. and Mincher, A. (2011) Computational Fluid Dynamic Analysis and Design Optimization of Jet Pumps. Computers \& Fluids, 46, 212-217. http://dx.doi.org/10.1016/j.compfluid.2010.10.024

[18] Raheel, M. and Engeda, A. (2002) Current Status, Design and Performance Trends for the Regenerative Flow Compressors and Pumps. ASME International Mechanical Engineering Congress \& Exposition, New Orleans, 17-22 November 2002, 99-110. http://dx.doi.org/10.1115/imece2002-39594

[19] Sixsmith, H. (1981) The Theory and Design of a Regenerative Compressor, Research Paper for Institute of Refrigeration. Institute of Marine Engineers, 69-77. 


\section{Notation}

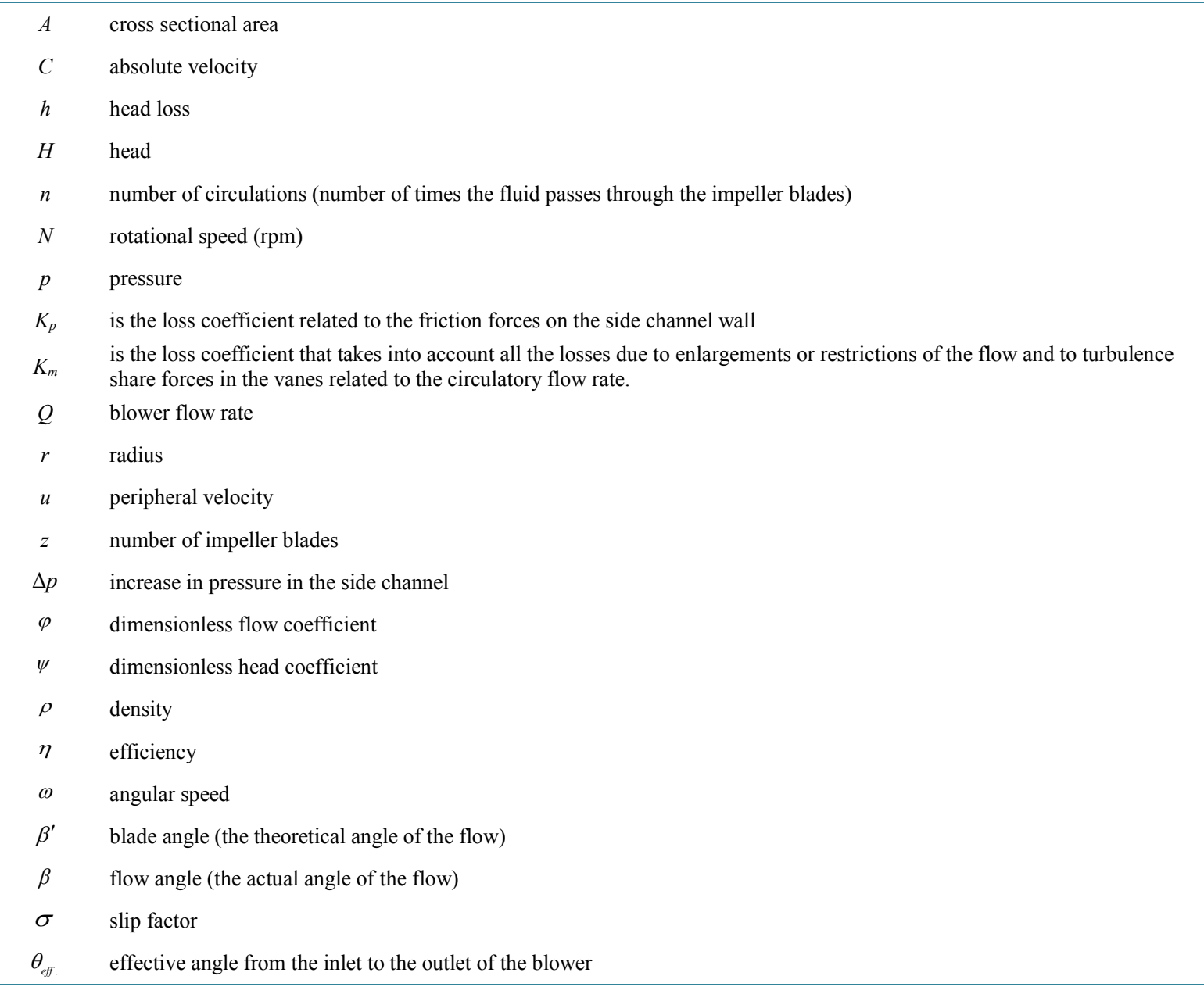

\section{Subscripts}

\begin{tabular}{cl}
1 & position of inlet flow to the impeller blade \\
$2 s$ & position of outlet flow from the impeller side \\
$2 t$ & position of outlet flow from the impeller tip \\
$C$ & channel \\
$c i r$ & circulation \\
$m$ & meridional (circulatory) component, mean value \\
$s$ & side \\
$t$ & tip \\
$u$ & tangential component \\
\hline
\end{tabular}

